\title{
Grace Periods in Sovereign Debt
}

\author{
Mehmet Bac*
}

\begin{abstract}
This paper presents a theoretical analysis of grace periods in the context of an overhang of external debt creating a tax on domestic investment. The grace period arises as a Nash equilibrium strategy of the creditor in a dynamic, noncooperative game. Its length is shown to depend on the planning horizon of the parties, the discount factor and the growth prospect of the debtor country.
\end{abstract}

\section{Introduction}

Theoretical analyses of debt relief schemes are based on the debt overhang argument, according to which the overhang of foreign debt impedes investment, and thus the future repayment capacity of highly indebted countries. The argument implies that debt relief schemes can have real effects and be mutually beneficial. Krugman (1989), Bulow and Rogoff (1988, 1989a), and Froot (1989) have examined the benefits of debt reductions, buybacks and other relief schemes under the debt overhang assumption. In most of this literature, the problem is reduced to a two-period analysis where default occurs when the economy, affected by a stochastic shock, falls into a "bad state of nature." Debt relief schemes are incorporated into this framework to investigate their impact on the country's consumption, investment, growth, and secondary-market value of debt. In this paper I provide a theoretical analysis of a debt relief scheme which has not attracted much attention, "grace periods." Throughout the analysis I will assume that the debtor country has unused investment opportunities with positive net present value, and show that the creditors' grace period offer is a direct cure.

Evidence for the debt overhang hypothesis is not conclusive, though the hypothesis has recently found strong support in papers by Borenzstein (1990) and Kaminsky and Pareira (1996). The latter contains a survey of the literature and an empirical analysis suggesting a robust negative impact of debt overhang on investment and growth. ${ }^{1}$

I utilize a simple one-sector growth model with features that resemble those in Lancaster (1973). The central planner of the debtor country allocates the output net of debt repayments between investment and consumption. If the country is not able to meet its contractual obligations, following the assumption usually made in the literature, it pays nonetheless a fraction of its output to the creditor unless the latter offers a grace period. ${ }^{2}$ Initially, the country and its creditor will negotiate and implement a debt repayments plan which may include a grace period. This plan will emerge as a Nash equilibrium of the dynamic game in which the creditor's strategy is to choose a time path of debt repayments, given the debtor country's capital accumulation process. And given the debt repayments path determined by the creditor, the debtor country's strategy is to determine a path of investment and growth.

The next section presents the game-theoretic model, which is analyzed in section 3. Section 4 draws some conclusions and discusses extensions.

\footnotetext{
* Bac: Bilkent University, Bilkent, Ankara, Turkey 06533. Tel: 90-312-2664190; Fax: 90-312-2664960; E-mail: bac@bilkent.edu.tr. I would like to thank N. M. Hung and an anonymous referee for very useful comments and suggestions. All remaining errors are mine.
} 


\section{The Model}

Consider a one-sector, single-technique economy. The interest rate, $r$, is assumed to be constant throughout the analysis. The planning horizon of the debtor country and its creditor is infinite (a brief discussion of finite planning horizons and their impact on grace periods is relegated to section 4 ).

The debtor country inherits a debt stock, $B$. Any negotiated restructuring of the debt occurs at this stage. At any given time $t$, the debtor country's productive capital stock, $K_{t}$, determines its output through the production function $f\left(K_{t}\right)$. For simplicity, I assume that the rate of depreciation of capital is zero. The country allocates the output net of debt repayments between investment and consumption. Its objective is to maximize the discounted welfare of the representative agent, $\int_{0}^{\infty} e^{-\delta t} U\left(c_{t}\right) d t$, where $\delta$ and $U\left(c_{t}\right)$ denote the discount rate of the central planner and the utility of consumption at date $t$. The function $U\left(c_{t}\right)$ is strictly concave.

To simplify the analysis, let the inherited debt $B$ be a perpetuity, so that regular debt repayments are $b=r B$. If the debtor declares its inability to meet regular debt repayments, then the creditor can extract at most a fraction $\alpha$ of the output as repayments. The defaulting country thus pays back $\alpha f\left(K_{t}\right)$. This "gunboat technology" which enforces repayments up to a certain limit is a standard assumption in the literature. Clearly, default will occur as long as $b>\alpha f\left(K_{t}\right)$.

There are three further assumptions: (A1) output $f\left(K_{t}\right)$ is increasing and strictly concave in $K_{t}$; (A2) the initial level of the capital stock $K_{0}$ is such that $r B=b>\alpha f\left(K_{0}\right)$ and $f^{\prime}\left(K_{0}\right)>\delta$; and (A3) there exists $K^{\mathrm{R}}$, a level of capital stock, such that $b=\alpha f\left(K^{\mathrm{R}}\right)$ and $f^{\prime}\left(K^{\mathrm{R}}\right) \geq \delta$. Assumption (A1) and $f^{\prime}\left(K_{0}\right)>\delta$ are standard in the classical growth literature. The latter implies that there will be growth, while $b>\alpha f\left(K_{0}\right)$ merely states that the debtor country is highly indebted $\left(K_{0}\right.$ is low with respect to the debt stock $\left.B\right)$. By (A3), there exists a feasible level of capital stock, $K^{\mathrm{R}}>K_{0}$, such that the debtor country makes a voluntary switch to regular debt repayments once it accumulates $K^{\mathrm{R}}$. On the other hand, $f^{\prime}\left(K^{\mathrm{R}}\right)>\delta$ guarantees that capital will be accumulated beyond $K^{\mathrm{R}}$. The date at which the capital stock attains $K^{\mathrm{R}}$ is denoted $T^{\mathrm{R}}$.

The creditor's problem is to determine the time path of rates of output transferred as debt repayments, $\left\{u_{t}\right\}$, which generates the highest present discounted value. If the country defaults at date $t, u_{t}$ may at most be set equal to $\alpha$. Note that the model's assumptions imply the debt overhang hypothesis: forcing the debtor country to pay more will decrease investment today, reduce growth and thereby the country's repayment-generating capacity tomorrow. This tradeoff may lead the creditor to set $u_{t}$ $=0$; i.e., to let the country pay no interest for some period of time, which is called a "grace period."

The formal statement of the creditor's problem is as follows:

$$
\max _{u_{t} \in[0, \alpha]} \int_{0}^{T^{\mathrm{R}}} e^{-r t} u_{t} f\left(K_{t}\right) d t+e^{-r T^{\mathrm{R}}} B
$$

s.t.

$$
\begin{aligned}
& K_{t}=K_{0}+\int_{0}^{t} v_{s}\left(1-u_{s}\right) f\left(K_{s}\right) d s \text { for } t \leq T^{\mathrm{R}}, \\
& K_{T R}=K^{\mathrm{R}},
\end{aligned}
$$

and subject to given $K_{0}$. In equation (2), $v$ denotes the fraction of output devoted to investment. This constraint is effective and the creditor takes into account the capital accumulation process until date $T^{\mathrm{R}}$, defined implicitly by (3) and (A3). Note that $T^{\mathrm{R}}$ 
will depend on the entire path of $\left\{u_{t}\right\}$, and $T^{\mathrm{R}}$ and $\left\{u_{t}\right\}$ will in turn depend on the debtor's investment policy, $\left\{u_{t}\right\}^{3}$

At each date $t$, the debtor's output net of debt repayments, $\left(1-u_{t}\right) f\left(K_{t}\right)$, is allocated between investment and consumption. $v_{t}\left(1-u_{t}\right) f\left(K_{t}\right)$ is added to the capital stock and what remains is consumed. The problem of the debtor is thus:

$$
\max _{v_{t} \in[0,1]} \int_{0}^{T^{\mathrm{R}}} e^{-\delta t} U\left(c_{t}\right) d t+e^{-\delta T^{\mathrm{R}}} V\left(K^{\mathrm{R}}, B\right)
$$

s.t.

$$
c_{t}=\left(1-v_{t}\right)\left(1-u_{t}\right) f\left(K_{t}\right)
$$

and equations (2) and (3). In the maximand stated in $(4), V\left(K^{\mathrm{R}}, B\right)$ represents the maximized welfare as viewed from date $T^{\mathrm{R}}$. It is obtained by solving the following problem:

$$
V\left(K^{\mathrm{R}}, B\right)=\max _{v_{t} \in[0,1]} \int_{0}^{\infty} e^{-\delta t} U\left(c_{t}\right) d t
$$

subject to $c_{t}=\left(1-v_{t}\right) f\left(K_{t}\right)-b$ and $K_{t}=K^{\mathrm{R}}+\int_{0}^{t} v_{s} f\left(K_{s}\right) d s$. The two players are thus placed in a game situation until date $T^{\mathrm{R}}$. I will use the open-loop noncooperative Nash equilibrium as the solution concept for this game.

It is worth reconsidering several features of the model before going through the formal analysis. The analysis focuses on a debt relief scheme given a large external debt generating a tax on investment, and leaves unexplained the reasons why and how the initial large, overhanging debt has been accumulated. Uncertainty, exogenous shocks, and the inherent moral hazard problems in sovereign lending are among the most cited reasons for this phenomenon. The dynamic game is one of complete and perfect information. The parties lack no information about each other's objectives and there is no external uncertainty nor shocks. It would be possible to extend the model to allow for future exogenous shocks on output; this would not change my qualitative results concerning the relationship between the length of grace periods and initial debt stock, expected growth prospects and the investment path of the indebted country. The analysis of this case would be more complex but it promises a richer set of potential outcomes (occasional default periods followed by consecutive bad realizations of output, possibly also reintroducing a grace period). A last point that should be mentioned is that I do not consider the possibility of additional lending, even after the country settles on its regular debt repayments path. This is assumed to keep the analysis simple and tractable, and because the possibility of relending seems tangential to the length of grace periods in the presence of an already large debt stock. ${ }^{4}$

\section{The Analysis}

The game defined by the objectives and constraints given in (1)-(6) can be solved backwards. First, consider the period after date $T^{\mathrm{R}}$ where the debtor is on its regular debt repayments regime. In this period, the debtor's problem is a standard one-sector growth problem with an initial capital stock $K^{\mathrm{R}}$. The Hamiltonian for this problem can be written as

$$
H^{\mathrm{DR}}=e^{-\delta t} U\left[\left(1-v_{t}\right) f\left(K_{t}\right)-b\right]+\gamma_{t}^{\mathrm{DR}} v_{t} f\left(K_{t}\right),
$$

where $\gamma_{t}^{\mathrm{DR}}$ is the costate variable or, as it is usually interpreted, the discounted valuation of a marginal investment. Defining $\lambda_{t}^{\mathrm{DR}}=e^{\delta t} \gamma_{t}^{\mathrm{DR}}$, the actual value of $\gamma_{t}^{\mathrm{DR}}$, one obtains 
the two necessary conditions $\lambda_{t}^{\mathrm{DR}}=U^{\prime}\left(c_{t}\right)$ and $\partial \lambda_{t}^{\mathrm{DR}} / \partial t=-\left\{f^{\prime}\left(K_{t}\right)-\delta\right\} \lambda_{t}^{\mathrm{DR}}$, coupled with the transversality condition $\lim _{t \rightarrow \infty} e^{-\delta t} \lambda_{t}^{\mathrm{DR}} K_{t}=0$. The first necessary condition states that along the optimal investment path the valuation of a marginal increase in the capital stock is equal to the foregone marginal utility of consumption. The second is obtained through the condition $-\partial H^{\mathrm{DR}} / \partial K_{t}=\partial \gamma_{t}^{\mathrm{DR}} / \partial t$. It yields an important dynamic property of the investment path: for $t \geq T^{\mathrm{R}}$, optimal investment rates $v_{t}^{*}$ must be consistent with the marginal utility of consumption diminishing at the rate $f^{\prime}\left(K_{t}\right)-\delta$. By the transversality condition, it follows that the capital stock must converge to a steady-state level $\bar{K}$ such that $\delta=f^{\prime}(\bar{K})$. The path of investment $v_{t}^{*}$ must decrease through time, approaching zero asymptotically as $t \rightarrow \infty$.

The dynamic game is effective in the period $\left[0, T^{\mathrm{R}}\right]$. A Nash equilibrium for the game described by (1)-(5) is a pair of control functions $\left(\left\{u_{t}^{*}\right\},\left\{v_{t}^{*}\right\}\right)$ such that $\left\{u_{t}^{*}\right\}$ solves the creditor's problem in (1) for $\left\{v_{t}\right\}=\left\{v_{t}^{*}\right\}$ and $\left\{v_{t}^{*}\right\}$ solves the debtor's problem in (4) for $\left\{u_{t}\right\}=\left\{u_{t}^{*}\right\}$. To find the Nash equilibrium of this game, we have two Hamiltonians, one for the creditor's problem and one for the debtor's problem:

$$
\begin{aligned}
& H^{\mathrm{C}}=e^{-r t} u_{t} f\left(K_{t}\right)+\gamma_{t}^{\mathrm{C}} v_{t}^{*}\left(1-u_{t}\right) f\left(K_{t}\right), \\
& H^{\mathrm{D}}=e^{-\delta t} U\left[\left(1-v_{t}\right)\left(1-u_{t}^{*}\right) f\left(K_{t}\right)\right]+\gamma_{t}^{\mathrm{D}} v_{t}\left(1-u_{t}^{*}\right) f\left(K_{t}\right) .
\end{aligned}
$$

For the creditor's problem, $u_{t}^{*}$ maximizes (7). This yields the following necessary condition:

$$
u_{t}^{*}=\left\{\begin{array}{lll}
0 & \text { if } & \gamma_{t}^{\mathrm{C}} v_{t}^{*}>e^{-r t} \\
\alpha & \text { if } & \gamma_{t}^{\mathrm{C}} v_{t}^{*}<e^{-r t},
\end{array}\right.
$$

and $u_{t}^{*} \in[0, \alpha]$ if $\gamma_{t}^{\mathrm{C}} v_{t}^{*}=e^{-r t}$. This is interpreted as follows. A fraction $v_{t}^{*}$ of one dollar of output is added to the capital stock and its discounted valuation from the creditor's viewpoint is $\gamma_{t}^{\mathrm{C}} v_{t}^{*}$. If $\gamma_{t}^{\mathrm{C}} v_{t}^{*}$ is less than $e^{-r t}$, the discounted value of one dollar of debt repayments, then the creditor will try to extract maximal debt repayments $\left(u_{t}^{*}=\alpha\right)$. Otherwise it will set $u_{t}^{*}=0$. The costate variable $\gamma_{t}^{\mathrm{C}}$ satisfies

$$
\frac{\partial \gamma_{t}^{\mathrm{C}}}{\partial t}=-\frac{\partial H^{\mathrm{C}}}{\partial K_{t}}=-e^{-r t} u_{t} f^{\prime}\left(K_{t}\right)-\gamma_{t}^{\mathrm{C}} v_{t}^{*}\left(1-u_{t}\right) f^{\prime}\left(K_{t}\right),
$$

and the corresponding transversality condition $\gamma_{T R}^{C}=0$, which represents the fact that the debtor country's investment projects have no effect on the creditor's objective beyond date $T^{\mathrm{R}}$.

As for the debtor country's problem, maximization of (8) with respect to $v_{t}$ yields $\gamma_{t}^{\mathrm{D}}=e^{-\delta t} U^{\prime}\left(c_{t}\right)$, where $c_{t}$ is defined by (5). Defining $\lambda_{t}^{\mathrm{D}}=e^{\delta t} \gamma_{t}^{\mathrm{D}}$ yields the familiar necessary condition $\lambda_{t}^{\mathrm{D}}=U^{\prime}\left(c_{t}\right)$. The corresponding transversality condition is $\lambda_{T \mathrm{R}}^{\mathrm{D}}=\lambda_{T \mathrm{R}}^{\mathrm{DR}}$, which requires that the debtor's valuation of a marginal increase in its capital stock be continuous at the neighborhood of $t=T^{\mathrm{R}}$. The evolution of $\lambda_{t}^{\mathrm{D}}$ can be obtained by taking the partial derivative of $H^{\mathrm{D}}$ with respect to the state variable $K_{t}$ :

$$
\partial \lambda_{t}^{\mathrm{D}} / \partial t=-\left\{\left(1-u_{t}^{*}\right) f^{\prime}\left(K_{t}\right)-\delta\right\} \lambda_{t}^{\mathrm{D}} .
$$

The conditions above contain all the information concerning the properties of the Nash equilibrium $\left(\left\{u_{t}^{*}\right\},\left\{v_{t}^{*}\right\}\right)$. First, $\gamma_{T \mathrm{R}}^{\mathrm{C}}=0$ implies that at the left neighborhood of $T^{\mathrm{R}}$ the creditor prefers not to leave the marginal dollar in the debtor country because its valuation falls short of its discounted value as debt repayments: $u_{t}^{*}=\alpha$. Using this fact in (10), the evolution of $\gamma_{t}$ at this neighborhood is given by 


$$
\partial \gamma_{t}^{\mathrm{C}} / \partial t=-(1-\alpha) v_{t}^{*} f^{\prime}\left(K_{t}\right) \gamma_{t}^{\mathrm{C}}-e^{-r t} \alpha f^{\prime}\left(K_{t}\right) .
$$

Equation (12) clearly shows that the path of $\gamma_{t}^{\mathrm{C}}$ is declining. The relevant question for the analysis is whether there exists a date $\tau$ such that $\gamma_{\tau}^{\mathcal{C}} \nu_{\tau}^{*}=e^{-r \tau}$. If yes, the optimality condition (9) would imply $u_{t}^{*}=0$ for $t \in[0, \tau]$, which means that the creditor offers a grace period $[0, \tau]$. The factors that affect $\tau$ are identifiable in (12). The most important of these factors is the evolution of the capital stock, hence that of the marginal productivity $f^{\prime}\left(K_{t}\right)$. Because the path of $\gamma_{t}^{\mathrm{C}}$ becomes steeper at low levels of $K_{t}$, such a date $\tau$ will exist if $K^{\mathrm{R}}-K_{0}$ is "sufficiently large." The term $K^{\mathrm{R}}-K_{0}$ captures the debtor country's growth prospect. The larger is this growth prospect, the more the process of capital accumulation merits the creditor's consideration and the higher is the duration of grace periods. A second important factor affecting the length of grace periods is the speed of capital accumulation, as captured by the path of $v_{t}^{*}$. This path has a negative slope owing to the concavity of $U\left(c_{t}\right)$ and to the fact that marginal utility must decline at a diminishing rate $\left|\delta-(1-\alpha) f^{\prime}\left(K_{t}\right)\right|$. Thus moving backwards in time, the path of $v_{t}^{*}$ becomes steeper. Combining this fact with (12) suggests that $\gamma_{t}^{\mathrm{C}} \nu_{t}^{*} \rightarrow e^{-r t}$ from below as $t \rightarrow 0$. A grace period may thus exist if the debtor country is willing to accumulate capital rapidly. This is intuitive: grace periods are most effective when the investment-disincentive effect of debt repayments is very high, which is most likely to be the case when $K_{0}$ and the debtor's discount rate $\delta$ are low. The value of $\delta$ is of particular importance. If the debtor government's planning horizon is expected to be short owing to political cycles, $\delta$ would be very high, the process of capital accumulation would be slow, and the creditor would be reluctant to offer a grace period even if the economy has a high growth prospect.

Invoking the perfect-foresight hypothesis, it can be shown that there will be a discontinuity on the path of $v_{t}^{*}$ at the end of the grace period. Since $\lambda_{t}^{\mathrm{D}}$ (the marginal utility of consumption) must evolve smoothly, consumption at the left and right neighborhoods of $\tau$ must be equal, $c_{\tau^{-}}=c_{\tau^{+}}$. This leads to $1-v_{\tau}^{*^{-}}=(1-\alpha)\left(1-v_{\tau}^{*+}\right)$, which implies a switch in the investment path by $v_{\tau}^{*-}-v_{\tau}^{*+}$.

\section{Concluding Remarks}

An important factor determining the effectiveness of grace periods, as mentioned in section 3, is the planning horizons of the parties. The planning horizons depend on election or political cycles in the debtor country and on pessimistic creditor beliefs concerning future debt repayments. Under pessimistic beliefs no grace periods may exist. This effect can easily be verified in a finite-horizon version of this model or by increasing the discount rates $\delta$ and $r$. When there are many creditors and one debtor, coordination problems among the creditors are also known to impede efficient agreements to offer debt relief, including grace periods. A dynamic analysis of the coordination problems with hidden actions for the indebted country will contribute to our understanding of dynamic creditor-sovereign borrower relationships.

This paper has emphasized that a comprehensive analysis of debt relief schemes should also include grace periods. Debt-relief "Laffer curves" obtained with and without grace periods may look quite different. Ruling out grace periods in the present model would mean that the creditors keep extracting the maximum fraction of output they can, which would yield an inefficiently long period of irregular, low repayments owing to the negative impact on domestic investment and growth. Debt forgiveness (i.e. a reduction in the initial stock of debt, $B$ ) works its effect indirectly by shorten- 
ing the length of the grace period and bringing the switch to regular debt repayments to an earlier date, and also generates faster growth. A critical level of initial debt stock can be found such that the discounted value of repayments is maximized by taking the partial derivative of the creditor's value function in (1) with respect to $B$ and setting it equal to zero. If the initial outstanding debt is higher, a debt forgiveness should be used, of course coupled with a corresponding grace period. A reduction in the outstanding debt would decrease the creditor's welfare otherwise, while a grace period may still be offered to maximize the discounted value of debt repayments by partly alleviating the tax on the debtor's investment.

\section{References}

Bac, Mehmet, "On the Term Structure of Sovereign Debt Contracts," Review of International Economics 3 (1995):174-85.

Borensztein, Eduardo R., "Debt Overhang, Credit Rationing, and Investment," Journal of Development Economics 32 (1990):315-35.

Bulow, Jeremy and Kenneth A. Rogoff, "The Buyback Boondoggle," Brookings Papers on Economic Activity 2 (1988):675-98. 1989a.

, Sovereign Debt Repurchases: No Cure for Overhang," NBER working paper 2850,

"A Constant Recontracting Model of Sovereign Debt," Journal of Political Economy 97 (1989b):155-78.

Froot, Kenneth, "Buybacks, Exit Bonds, and the Optimality of Debt and Liquidity Relief," International Economic Review 30 (1989):45-70.

Kaminsky, Graciela L. and Alfredo Pereira, "The Debt Crisis: Lessons of the 1980s for the 1990s," Journal of Development Economics 50 (1996):1-24.

Krugman, Paul R., "Market-Based Debt-Reduction Schemes," in Jeffrey A. Frenkel, Mark P. Dooley, and P. Wickham (eds.), Analytical Issues in Debt, Washington DC: IMF, 1989.

Lancaster, Kevin, "The Dynamic Inefficiency of Capitalism," Journal of Political Economy 81 (1973):1092-109.

Sachs, Jeffrey A. (ed.), Developing Country Debt and Economic Performance, Chicago: Chicago University Press, 1990.

Symposium on New Institutions for Developing Country Debt, Journal of Economic Perspectives 4 (1990):3-55.

\section{Notes}

1. See also the collected papers in Sachs (1990) and the Symposium on New Institutions for Developing Country Debt in the Journal of Economic Perspectives (1990) for the pros and cons of this hypothesis.

2. The theoretical and empirical justification of this assumption can be found in Bulow and Rogoff $(1988,1989 b)$. The creditors' hindering the trade of the defaulting country in world goods and capital markets exemplifies this enforcement technology.

3. The variable $u_{t}$ corresponds to the variable " $q$ " in Bulow and Rogoff $(1988,1989 \mathrm{~b})$. I allow the creditor to choose this variable in the interval $[0, \alpha]$.

4. Another modeling possibility would be to consider a finite-maturity debt. This would bring in additional considerations, such as rescheduling of both debt repayments and maturities, but could be considerably more complex than the present model. See Bac (1995) for an infinitehorizon, constant-output sovereign lending model that endogenizes both loan sizes and maturities. 